Portland State University

PDXScholar

1971

\title{
Implications of an oral-gestural training program in the acquisition of speechreading skills
}

Mary Lu Wood

Portland State University

Follow this and additional works at: https://pdxscholar.library.pdx.edu/open_access_etds

Part of the Speech and Hearing Science Commons, and the Speech Pathology and Audiology Commons

Let us know how access to this document benefits you.

\section{Recommended Citation}

Wood, Mary Lu, "Implications of an oral-gestural training program in the acquisition of speechreading skills" (1971). Dissertations and Theses. Paper 1476.

https://doi.org/10.15760/etd.1475

This Thesis is brought to you for free and open access. It has been accepted for inclusion in Dissertations and Theses by an authorized administrator of PDXScholar. Please contact us if we can make this document more accessible: pdxscholar@pdx.edu. 
AN ABSTRACT OF THE THESIS OF Mary Lu Wood for the Master of Science in Speech with a major emphasis in Speech Pathology and Audiology presented July 2, 1971.

Title:(Implications of an Oral-Gestural Training Program in the Acquisition of Speechreading Skills

APPROVED BY MEMBERS OF THE THESIS COMMITTEE:
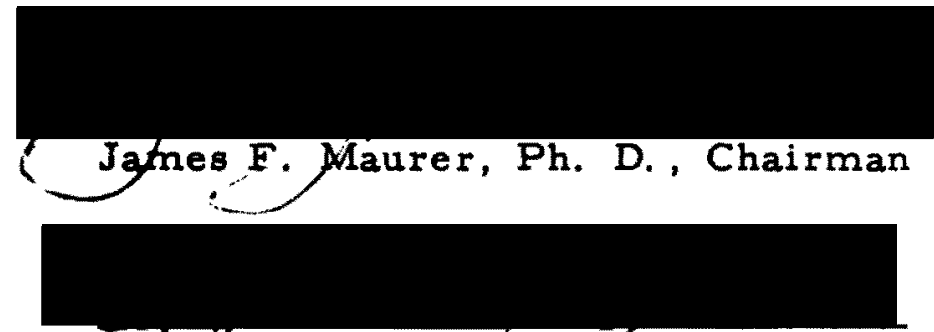

Robert H. English, D. Fd.

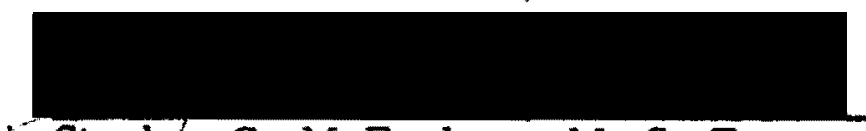

Stephen C. McFarlane, M. S. T.

In order for the hearing handicapped child to derive maximum benefit of language acquisition through maturation, a method of receptive communication is essential at the earliest age possible. It is felt that speechreading is this method. The need for a method of training speechreading cues to prelingual, aurally handicapped children is based on the fact that most visual speechreading methods require the use of language: If speechreading can be regarded as a learning process involving the discrimination of visual cues that may 
be disassociated from language expression, then training the child to discriminate various facial expressions may actually enhance speechreading ability. If such a training method proved to be highly connected with speechreading learning, then it also might prove useful in helping the deaf pre-school child acquire the necessary attentive and discriminitive behaviors consistent with speechreading.

Ten pre-school, normal hearing children participated in an oral-gestural training program which was carried out in three parts:

1) Administration of the revised Children's Speechreading Test,

2) Training for discrimination of oral-gestural pairs as "same" or "different" until a 100 percent correct response criterion had been obtained, 3) Evaluation of the oral-gestural training through readminiatration of the revised Children's Speechreading Test.

A t-test of the difference between the baseline mean and post training speechreading mean revealed significance beyond the .05 level of confidence. This supported the original proposal that speechreading skills for propositional words can be acquired by means of visual discrimination training in oral-facial movements.

It is thus proposed that such training will prove useful in helping the hearing handicapped preschool child acquire the necessary behaviors consistent with speechreading, namely attention and visual discrimination.

This study involved normal hearing subjects in which language 
was already established. Since the Oral-Gestural Training program is designed for the hearing handicapped prelingual child, further investigation with such a population appears necessary to confirm the findings of this investigation. Other questions that arose during the study such as sex and age differences of a larger sample, and the significance of the number of oral-gestural training sessions as related to the post-training test score, are other related areas that need consideration before a final conclusion can be drawn. Although no formal data was obtained on attention span, it was observed subjectively that this capacity improved markedly among the se subjects. This is a clinical observation and should be subjected to further investigation. In conclusion, it appear through the findings of this study, that such a training method may be highly related with speechreading training and may indeed prove useful in helping prelingual, aurally handicapped children acquire the necessary behaviors consistent with speechreading. 


\title{
IMPLICATIONS OF AN ORAL-GESTURAL TRAINING PROGRAM \\ IN THE ACQUISITION OF SPEECHREADING SKILLS
}

\author{
by
}

MARY LU WOOD

A thesis submitted in partial fulfillment of the requirements for the degree of

\author{
MASTER OF SCIENCE \\ in \\ SPEECH \\ with emphasis in Speech Pathology \\ and Audiology \\ Portland State University \\ 1971
}


TO THE OFFICE OF GRADUATE STUDIES:

The members of the Thesis Committee approve the thesis of Mary Lu Wood presented July 2, 1971. .
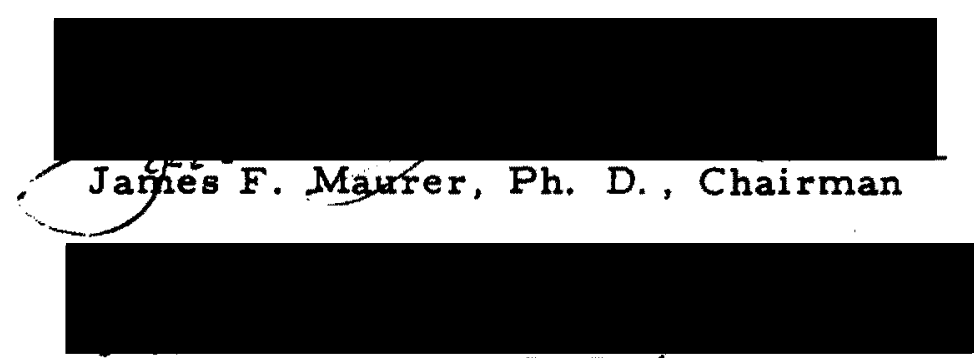

Robert H. English, D, E\%.

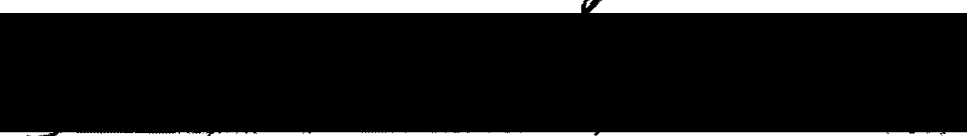

Stephén C. McFarlane, M.S. T.

APPROVED:

Robert W, Vogelsang/Chairmaf, Department of Speech

David T. Clark, Dean of Graduate Studies 


\section{ACKNOW LEDGEMENTS}

Most sincere appreciation is expressed to Dr. James F. Maurer for his understanding, direction, and support in the development of this manuscript.

Deep gratitude also is expressed to Mr. Dick Frey, a student of Speech and Hearing at Portland State University, who so willingly and patiently assisted in retesting.

To the children, staff and management of the Fruit and Flower Nursery who were so cooperative, I am most grateful. 
TABLE OF CONTENTS

PAGE

ACKNOWLEDGEMENTS . . . . . . . . . . . . . iii

LIST OF TABLES . . . . . . . . . . . . . . . . . vi

CHAPTER

I INTRODUCTION . . . . . . . . . . . . 1

Purpose of the Study . . . . . . . . . . 4

II HISTORY . . . . . . . . . . . . 6

III THE TRAINING PROGRAM . . . . . . . . 18

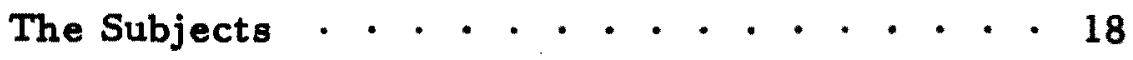

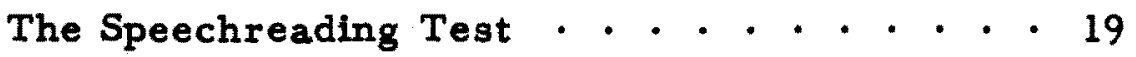

The Physical Environment . . . . . . . 19

Oral-Gesture . . . . . . . . . 20

The Reinforcers. . . . . . . . . . 21

The Response Events. . . . . . . . . . . . 23

The Procedures... . . . . . . . . 23

IV RESULTS . . . . . . . . . . . . . 27

V SUMMARY AND CONCLUSIONS . . . . . . . 34

Purpose of the Study . . . . . . . . . . . 34

The Training Program . . . . . . . 34

Results. . . . . . . . . . . 35 


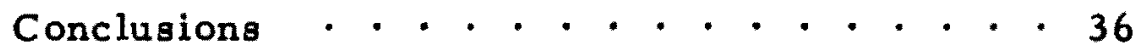

Implications for Further Study * * . . . . - 37

BIBLIOGRAPHY • • • • • • • • • • • • • APPENDIX

A Revised Children's Speechreading Test . . * 41

B Oral-Gestural Schedule • . . . . . . . 52

C Pretest Instructions . . . . . . . . . . 55

D. Oral-Gestural Training Instructions • • • • • 56

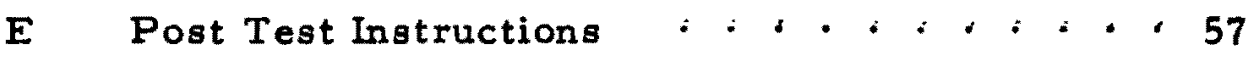




\section{LIST OF TABLES}

$\div \perp E \pm E$

PAGE

I A Summary of Data Derived From the OralCestural Training Program . . . . * . . . . 27

IIncrease in Speechreading Scores after OralGestural Training . . . . . . . . . . . . 28

III Mean Increase in Speechreading Scores - Sex • • 30

IV Mean Increase in Speechreading Scores - Age • • 31 


\section{CHAPTER I}

\section{INTRODUCTION}

Language is learned through both the eye and the ear. Even people with normal hearing use speechreading to supplement auditory cues in understanding speech. Speechreading for the deaf is essential in order to understand oral communication. Success for a hearing handicapped individual in school and society depends largely on his ability to use language, most particular the spoken language.

Visual cues for the deaf or the hard-of-hearing assume a more important role in communication than for the normal hearing individual. Body movement, gestures and facial expression become increasingly significant as signals of communication for transmitting ideas and information. When the sounds of speech are received in their full intensity, visual cues play a secondary role. To the deaf infant, visual cues are primary. Even to the hard of hearing they are more heavily relied upon than in the normal hearing infant. Additional responsibility must be placed upon the eye as an information receiver if the ear fails to respond normally to sound.

The infant is born with visual hunger. Although he resists excessive illumination by blinking, he very soon uses his waking time for accumulation of visual experiences and the exercise of the ocular functions (Gesell and Amatruda, 1947).

Through this "visual hunger" and natural interest in the human face, 
the hearing handicapped infant can learn the meaning of words through speechreading very early in life if he is given the opportunity.

As soon as a hearing loss is detected the best possible environment for language development should be provided. According to Ewing (1948) "the infant and young child are not taught speechreading, but through wise management, this skill is encouraged and given an opportunity to grow." Although opinions vary as the most desirable sequence of training of visual and auditory skills, all agree on the importance of the early years of language learning.

Educators of the deaf have long been aware of the desirability and necessity for beginning training early. As McNeill (1966) states:

In view of the possibility of a critical period for language acquisition, which peaks at two to four years and declines steadily thereafter, an effort to take advantage of a deaf child's capacity for language acquisition must be an early effort--the earlier the better.

Experienced teachers of the deaf have found that their only hope for success is to begin early and stimulate the child through every sensory channel available. The effects of early training have been favorable, and early stimulation has been known to develop speechreading ability in children of a year or less (Ewing, 1948).

Comprehension of language is important to the deaf child, but of equal importance is expressive language or speech.

Once a severe degree of deafness is found or even suspected in a child, the whole aim of subsequent treatment is to enable the child to progress through the stages of acquiring speech in 
the same way as the hearing child (Fry, 1966).

One of the essential stages of speech acquisition is learning the cues for sound production.

Speechreading is one of the most important means of teaching the language and the art of communication that is available to the deaf and hard of hearing. The child who can receive communication is more naturally motivated to send communication. If a method of training discrimination for speechreading cues to prelingual, aurally handicapped children was available, perhaps earlier receptive communication skills might be achieved. This would put the child on the road toward learning other aspects of communication.

\section{PURPOSE OF THE STUDY}

The need for a method of training speechreading cues to prelingual, aurally handicapped children is based on the fact that most visual speechreading methods require the uses of language. If speechreading can be regarded as a learning process involving the discrimination of visual cues, the training aimed at teaching the child to discriminate small changes in facial movements may well provide for some of the same behaviors necessary for speechreading language responses. Oral gestures are facial postures that may be disassociated from language expression, such as pursing the lips, retracting the lips, opening the mouth, closing the mouth. Consequently, a 
discrimination task aimed at teaching the child to detect and respond appropriately to the changes in facial movement may be closely associated with speechreading activity. If such a training method proved to be highly connected with speechreading training, then it also might prove useful in helping the hearing handicapped pre-school child acquire the necessary behaviors consistent with speechreading, namely attention and discrimination.

It is the purpose of this study to seek to determine whether a visual discrimination training program will facilitate the acquisition of speechreading responses. This will be tested by using a sample of pre-school, normal hearing children in three parts. The first part will include a baseline score on the revised Children's Speechreading Test (Russell and Folsum, 1969). The second part will be the oralgestural training period. The last part will involve retesting speechreading in order to compare the post-training scores and the baseline scores. 


\section{CHAPTER II}

\section{HISTORY}

The growth of speechreading instruction coincides with the growth and development of the education of the deaf. One of the earliest references to deaf education was written by Bede in $700 \mathrm{~B}$. C., about a John of Beverly, who taught a "deaf and dumb" person to speak intelligibly (DiCarlo, 1964). This accomplishment was attributed to a miracle. Early education of the deaf was often shrouded in mystery and the mystical. Church literature at the early date of 500 B. C. (Davis and Silverman, 1970) exhorted the faithful not to curse the deaf since their deafness was presumably willed by the Lord. In the second century B. C., the rabbis of the Talmud classified the deaf with fools and children.

For many years the deaf were considered lacking intelligence and thought to be incapable of learning, infering that those who were born deaf were mentally deficient. This appears to have been a conclusion drawn through mistranslation and misinterpretation of an observation of Aristotle--384-322 B. C. --where he said that even though the deaf had voice, they were speechless. Speechlessness was translated as dumb, and "dumb" has the dual meaning of being without intellect (Deland, 1931; O'Neill and Oyer, 1961). 
Roman Law, as early as 500 A. D., recognized the deaf and made provisions for them in their laws. Roman Law classified the deaf and dumb with the mentally incompetent (DeLand, 1931). The Justine Code excluded the deaf and dumb from the rights (entering into contracts, etc.) and obligation (witnessing in the courts of law) of citizenship. The Justine Code influenced later medieval law to deny to the congenitally deaf and dumb the cherished right of inheritance to the oldest son (DeLand, 1931; DiCarlo, 1964 and Davis and Silverman, 1970).

In the early sixteenth century, however, the Italian philosopher and physician, Jerome Cardan, demonstrated that education of the deaf was not futile, that their organs of speech could be made effective and they, therefore, were not doomed to social inadequacy (DeLand, 1931; Davis and Silverman, 1970).

The beginning of education for deaf-mutes did not center around the cultural fervor of the Renaissance, instead it came to be based on the religious beliefs advocated by zealous monastic orders. Pedro Ponce de Leon, a monk and a Spanish contemporary of Jerome Cardan, is considered to be the first teacher of the deaf. He educated only the deaf from noble families. The rationale for this was so that they might achieve religious salvation, and by learning some form of communication, they would be permitted to inherit their family properties (Davis and Silverman, 1970). 
From the middle of the sixteenth century there was a progressive increase in educational opportunities for the acoustically handicapped. Early endeavors in the teaching of lipreading emerged from ideal conditions: small teacher-pupil ratio, devoted teachers, high compensation, and discrimination in pupil selection.

The first known book dealing with lipreading was The Method of Teaching Deaf Mutes to Speak published in 1620 in Madrid by Juan Pablo Bonet (O'Neill and Oyer, 1961). Bonet did not feel that lipreading could be taught to everyone and that the successful lipreader would learn to lipread his teacher, but that his training would not be transferable to other lipreading situations. He believed that lipreading skills were dependent mainly on the individual's powers of attention rather than on the teacher's skills.

In 1648 John Bulwer, an English physician, wrote Philocopus, or The Dumb Man's Friend in which he felt that lipreading was important as an avenue through which the deaf could learn to speak (DiCarlo, 1964). It appears that the beginning of enlightment concerning the intellectual capabilities of the deaf is best typified by a quotation from Dalgarno's Didascalocophus, published at Oxford in 1680.

Taking it for granted, that deaf people are equal, in the faculties of apprehension, and memory, not only to the blind; but even to those that have all their senses: and having formerly shewn; that these faculties can as easily receive, and retain, the Images of things by the conveiance of Figures, 
thro the Eye, as of Sounds thro the ear: It will follow, that the Deaf man is, not only as capable, but also as soon capable of Instruction in Letters, as the blind man. And if we compare them, as to their intrinsick powers, has the advantage of him too; insomuch as he has a more distinct and perfect perception, of external Objects, then the other.... I conceive, there might be successful addresses made to a Dumb child, even in his cradle.... (Davis and Silverman, 1970).

It was this same George Dalgarno, a Scotsman, who advocated using letters of the alphabet on the finger tips and palm of the hand in the mid eighteen hundreds.

Dr. William Holder, a clergyman from Oxforshire, England, is considered to be one of the first teachers of the deaf in England. While he was Rector of Bletchington in 1659 , he was requested to teach a ten-year-old boy who had been deaf from birth. He later presented an account of his method in a book, Elements of Speech.

Now, as to the most general case of those who are Deaf and Dumb, I say, they are Dumb by Consequence from their Deafness, only because they are not taught to speak.... The Tong and the Ear, Speaking and Hearing, hold a correspondence by which we learn to imitate the Sound of Speech and understand the meaning of it.... Finding a deaf person.... there is no way to educate him but to have recourse to the other Learning Sense, which is Seeing; and to find out some means of instructing him by his Eyes, and showing him the visible motions and figures of the mouth, by which Speech is articulated (Goldstein, 1933).

Johann Konrad Amman, a Swiss physician who practices medicine in Holland, became interested in teaching deaf-mutes. He was so successful that in 1692 he published his techniques so that deaf children not only on the continent but also in England could benefit from his methodology. The following list of his major techniques 
show his belief and emphasis of oral-language education (DiCarlo, 1964):

1. Names of familiar and obvious things were taught first in the manner of educational methodology.

2. The pupils learned speech by seeing the position of the different sounds. The use of mirrors was advocated for practicing speech, and the sense of touch was utilized for sounds which were not immediately visible. The pupils were able to learn the voiced sounds by touching their hands to their throats.

3. Amman's main concern was that the deaf develop their voices clearly and maintain the ability to control pitch and loudness.

4. Amman employed lipreading as an integral part of learning language and communication. He even had his pupils take lipreading dictation as he mouthed sentences from a book.

Amman's accounts of his oral-teaching methods were influential in establishing the oral method of education in Germany.

The eighteenth century witnessed an increased attention and interest in the problems of the deaf throughout Europe. The beginning of national systems of education of the deaf were finally beginning to be established.

Henry Baker of England in 1720 taught a young deaf girl to read, to write, and to lipread. He was so encouraged by his success that he started a small private school. Henry Baker, however, kept his techniques a secret--so much so, in fact, that he asked a bond of one hundred pounds from each pupil to insure their secrecy $\left(O^{\prime} N e i l l\right.$ and 
Oyer, 1961). Working with the deaf in France at this same time was a Spaniard, Jacob R. Pereire, who taught both the manual alphabet and lipreading. Pereire also neglected to write down his approach to lipreading, so we know nothing of his techniques today (DiCarlo, 1964).

Charles M. de l'Epee, a contemporary of Pereire, began the first school for the aurally handicapped children of Paris. He realized the importance of teaching lipreading and speech to the se children that they might be a real part of and participate in society (DeLand, 1931). Enrollment was so great, however, that he was forced to teach the manual method which required less time, concluding that the manual method offered the shorter route and practical results because of its power to give greater clarity, movement, color, and alertness to the expression of ideas and thoughts (DeLand, 1931).

As the manual method became more and more accepted in France, the oral method was promoted in Germany by Samuel Heinicke (1729-1790). He felt that speech was necessary for clear thought by the deaf and that by watching the motion of a speaker's lips the deaf could learn to understand. Samuel Heinicke founded the first public school for the deaf in Germany and wrote exhaustively on the advantages of speech and speechreading (DeLand, 1931).

Thomas Braidwood, an educator in Scotland during the eighteenth century, became interested in teaching a deaf child to speak at the 
school where he taught mathematics (DeLand, 1931). Eventually his work was devoted exclusively to the education of the deaf and it was reported that his students seemed to hear with their eyes. After reporting marvelous successes with a few deaf pupils, he desired to instruct other teachers in his techniques so they could assist with the ever growing number of deaf pupils, and he wanted scholarship funds established for those who could not afford a formal education. He received no public encouragement. Bitter and disillusioned, he refused to divulge his method without proper safeguards and profits (Di Carlo, 1964).

John Braidwood, the grandson of Thomas Braidwood, after being persuaded by some very influential Americans migrated to the United States to set up a school for the deaf in 1815. After several attempts, he personally was unsuccessful in directing a school for the deaf (O'Neill and Oyer, 1961).

Thomas Gallaudet, a Yale graduate and a minister, went to England in 1815 to learn the Braidwood's methods of instruction. The Braidwoods, however, were not willing to share their methods with someone who would return and compete with young John Braidwood whose work was already in America. So, Gallaudet went to France where the manual method was advocated and studied under Abbe Secard in Paris. Gallaudet later returned to America and established what is now known as the American School for the Deaf (O'Neill and 
Oyer, 19611 .

After Gallaudet had returned from studying the French techniques rather than Braidwood's oral techniques, the manual method under his influence, became the primary system of deaf education to be used in the early American schools. The number of schools for deaf children rapidly grew until they reached twenty-two in 1860 , with the number of deaf children in these schools estimated at two thousand (DeLand, 1931).

Circumstances thus dictated that American schools for the deaf adopt the manual approach. The spectacular success of the manual method and the prevalent theory of that time, that the deaf were actually unable to speak, contributed to its acceptance. Nevertheless, educators gradually began to notice the success of the oral method as it was taught in England and Germany.

"A father's love is a powerful force," and due to a father's love for his little Mable, who became deaf after an attack of meningitis at four years of age, Gardiner Hubbard refused to accept the fact that his daughter would be denied the speech of normal children. It was through his determination, leadership and generosity that a private school was opened in 1866 at Chelmsford, Massachusetts, based upon the oral approach. Shortly after the opening of the private school, this same father petitioned for a state-financed oral school which had been repeatedly voted down by the Massachusetts 
legislature and was now approved by the Governor (DeLand, 1931; DiCarlo, 1964). Two years later, an oral day school, the Boston School for Deaf-Mutes, was opened. It was in 1867 that Alexander Graham Bell, who was teaching the Visible Speech System that his father Melville Bell had originated, established the oral day school in Boston (DeLand, 1931; DiCarlo, 1964).

Until the $1890^{\prime}$ s lipreading was taught primarily to children. One of the first teachers of adults, Lillie E. Warren, trained her pupils to associate certain numbers with certain sounds and referred to it as the Numerical Cipher Method (DeLand, 1931; O'Neill and Oyer, 1961).

Much emphasis was placed upon teaching the student to analyze mouth positions as the various sounds were produced. Mrs. Alexander Graham Bell, in 1894, was probably one of the first who felt that the speechreader should aim to grasp a speaker's whole meaning rather than to understand each word--she advocated a more synthetic approach. At the Fourth Summer Meeting of the American Association to Promote the Teaching of Speech to the Deaf in 1894, Mrs. Alexander Graham Bell read a comprehensive paper viewing the whole subject of lipreading from the point of view of the deaf child and of the hard-of-hearing adult. It was far ahead of its time and may still be read today as a modern and authentic exposition of speechreading (DeLand, 1931). She stated that speechreading was the "systematized 
result of practice" necessary to be able to read rapid speech, stating that the synthetic methods of practice were far superior to the prevailing practice which taught the student to analyze mouth positions as various sounds were produced. The primary aim should be to grasp the speaker's whole meaning rather than to try to understand each word or even each sentence. Mrs. Bell, who was deaf herself, learned to speak and lipread in early childhood and thus spoke from actual experience and not as one interested in just expanding one particular method over another (O'Neill and Oyer, 1961).

In the twentieth century, the problems of the deaf have received more attention by all professional disciplines. Oral education of the deaf has moved forward rapidly. Dr. James Kerr Love, a Scottish surgeon, had demonstrated in the late $1800^{\prime} \mathrm{s}$ that most deaf children have a certain amount of residual hearing. This encouraged educators to broaden the scope of oralism to include ear training, as well as lipreading (DiCarlo, 1964).

Eventually it became established practice to utilize both residential and day facilities for educating the deaf. Deaf children were accepted in these schools at an early age. Differential diagnostic techniques were employed to distinguish the deaf from the mentally deficient and the hard-of-hearing, neither of whom would derive maximum benefit from the improved additional methodologies developed specifically for the deaf children. Currently, the objectives of the 
education of the deaf are consistent with those of education itself. As the oral method has gained acceptance and grown, so have the specific methods for teaching speechreading. The Bruhn Method of lipreading, developed by Martha Bruhn, was based largely upon syllable drill and close observation of the movements of the lips from one sound position to another as she had learned from Herr Julius Muller-Walle in Germany, She was so successful that in 1902 she founded her own school in America (O'Neill, 1961).

Edward B. Nitchie, who was deaf from the age of fourteen, began teaching deaf children regular school subjects in a school he opened in 1903. The demand for lipreading instruction from adults, however, became so great that he directed his attention exclusively to adults.(DeLand, 1931; O'Neill and Oyer, 1961).

In 1914, Cora Kinzie opened her school of lipreading in Philadelphia teaching her own method of lipreading which incorporated the classification of introductory sounds from Bruhn and some basic psychological ideas from Nitchie. Later she and her sister Rose, a public school teacher, developed a series of graded lessons in lipreading (O'Neill and Oyer, 1961).

The Jena Method of Karl Brauckmann from Jena, Germany, was translated into English in 1926. The Jena Method of lipreading employs kinaesthetic as well as visual cues (O'Neill and Oyer, 1961). In more recent time, the use of films has been employed to 
teach speechreading, but their use in testing dates back to 1915

(O'Neill and Oyer, 1961). It appears that since 1930 no new or peculiar method has come forth, but rather procedures that are based on one or a combination of the early methods.

There seems to be informal agreement among teachers of lipreading that their most successful students should have a high ability to synthesize meaningful wholes from fragmentary parts. This synthetic ability seems to be the only one on which there is relative unanimity of opinion. Much less agreement appears to be found among teachers with regard to other abilities (Simmons, 1959). A survey of the literature yields a varied list of factors that might be related to lipreading such as the individual's age, intelligence, education, language and reading ability, synthetic ability and the perception of color and form, but there is a lack of agreement among investigators as to the degree of the relationship. There is also a wide variation in the population investigated. Some were normal hearing subjects, some congenitally deaf children, and others deafened adults. There is a lack of consistency in the measures of lipreading ability, including speaking with subjects, using teacher's evaluations, and the use of several different silent movie films in testing.

Low correlation has been found between speechreading and intelligence, education, language, reading, perception of color and form, and visual memory. Investigation of other factors such as 
personality, tactile reinforcement, and rythmn are limited in number and there appears to be a lack of agreement among these investigators. The only significant factors related to speechreading are the ability to synthesize and chronological age, and these findings are inconclusive (Simmons, 1959).

The question of what abilities are associated with lipreading is an old one which to this date has still not been precisely answered. The term lipreading is somewhat misleading in that lip movements provide only 14 to 17 percent of the speech sounds which are visually distinguishable, and only about one-third of the speech sounds are clearly visible (McNeill, 1966). Lipreading ability, often more appropriately called speechreading, consists of a pair of interdependent elements; that of recognizing physical movements and the ability to synthesize fragmentary parts into a meaningful whole. The integration of these two factors into a whole is considered to be the goal of speechreading training. Visual stimuli not associated with propositional speech is referred to as oral-gestures (Maurer, 1968). If such non-propositional visual stimuli can aid in the recognition and discrimination of physical movements that take place during the act of speech, then it may be entirely possible to teach speechreading to the prelingual deaf or hard-of-hearing child. 
CHAPTER III

\section{THE TRAINING PROGRAM}

It is the intent of this study to (1) obtain a baseline score on the revised Children's Speechreading Test, (2) train for the discrimination of oral-gestures and (3) retest speachreading in order to compare the post-training scores and the baseline scores. The purpose of this chapter is to describe an oral-gestural training program aimed at increasing the discrimination of movements of the oral structures. This will include a description of the following: The subjects, the speechreading test, the training period, the oral-gesture, the physical environment, the reinforcers, the response events, and the procedures.

\section{THE SUBJECTS}

Twenty-one children were selected randomly from the class rooms of four and five year old children at the F ruit and Flower Nursery in Portland, Oregon. A sample of ten preschoolers, five boys and five girls who were "poor" speechreaders as defined by a score of twenty-five or less correct out of seventy items on the revised Children's Speechreading Test, were chosen to participate in the oral-gesture training program. All of the participants had 
normal hearing as determined by a sweep frequency pure tone audiological screening test administered at $15 \mathrm{~dB}$. Socio-economically, these children were from middle class American homes.

\section{THE SPEECHREADING TEST}

The Children's Speechreading Test is a test designed by Deloris S. Butt and Fred M. Chreist (1968) specifically for the child who has not yet learned to read. The easiest items on the test can be performed by a one-year-old child. These items appear in the check list that precedes the formal test. The more difficult items requiring abstract language are usually understood by the three-year-old child (Butt and Chreist, 1968).

In the present study the Children's Speechreading Test, as revised by Mary E. Russell and Richard C. Folsom, at Portland State University, 1969, was used. The revised test includes the checklist of all seventy scorable items of the original test but some of the carrier phrases have been made more complete and there are more detailed instructions to the examine $r$ than in the original test (see Appendix A).

\section{THE PHYSICAL ENVIRONMENT}

The testing and oral-gesture training was done in a twelve by eight foot room at the Fruit and Flower Nursery. This room was used 
as a supply room and was not the most ideal testing and training environment, but it was the only room available at the Fruit and Flower Nursery where it would be free of interruptions.

A table was placed in the middle of the room with the child seated at one end and the examiner at the other end with a distance of four feet between them. The child was seated facing the bare wall where there would be a minimum of visual distractions within his periphery. During the testing, the table was clear except for the presentation of test items to be identified. During the oral-gestural training period, a pegboard for marking correct responses was placed in front and slightly to the left of the subject. A manual dispensing box used for presentation of the peg was placed on the table to the right of the subject with the instructor being directly in front of the child at the other end of the table.

\section{ORAL-GESTURE}

An oral-gestural program is aimed at increasing the discrimination of movements of the oral structures. Oral-gestures, which are facial postures not associated with language expression, were presented to the child in pairs, the two gestures of a pair being either the same or different. One oral-gesture was presented, i. e. open mouth wide, by the experimenter followed by a pause of two seconds with the instructor's mouth in resting position (lips together, muscles 
relaxed). Then the second oral-gesture of the pair was presented, i. e. open mouth, tongue straight out. The two oral-gestures were presented in groups of five pairs, each group in an ascending order of difficulty (see Appendix B). The five oral-gestures pairs were given as a group, each time in random order (see Appendix B for order of presentation) and thus avoiding the possiblity of the child learning the pattern of correct responses.

A discrimination score of 100 percent was required for each group of five before moving on to the next group of oral-gestures. The 100 percent criterion was reached only after the child had correctly discriminated five consecutive oral-gesture pairs.

\section{THE REINFORCERS}

During administration of the Revised Children's Speechreading Test, social reinforcement in the form of smiling, nodding, a pat on the back, and verbally expressing what a good helper he was, was freely given. This social reinforcement was contingent only upon the subject responding to the question regardless of whether a correct or incorrect answer was given. An $M$ \& $M$ was given on a variable ratio schedule at the end of each page, which represented an average of ten responses.

During the oral-gestural training period the subject was reinforced for each correct response by receiving a colored peg which 
was presented by sliding the peg through a tube in the manual dispens ing box. The peg came out of the mouth of a happy face painted on the end of the box facing the subject. The pegs were then placed by the subject in a peg board which consisted of twenty-five holes, five holes in each of five rows. When a row of pegs had been earned by the subject, an $M$ \& $M$ was given to the subject. When twenty-five pegs had been earned, a small plastic trinket could be selected by the subject to be put on a necklace which was presented at the beginning of the training program. The child was instructed that after final testing the completed necklace could be taken home. Five groups of five oral-gesture pairs were presented in ascending order of difficulty. A one-hundred percent correct criterion of five consecutive oral-gesture pairs was required before presentation could begin on the next group of oral-gestures.

The oral-gestural training sessions were approximately twenty minutes in length. Two to eight training sessions were required by individual subjects to meet the 100 percent criterion for all twenty five oral-gesture pairs.

The last part of this study involved the post-testing. Each subject was retested after completing the oral-gestural training period using the revised Children's Speechreading Test. Basically the same instructions were given to each subject (see Appendix D). The same random reinforcement for social rewards and a variable ratio for 
M \& M's were used.

A second examiner administered the revised Children's Speechreading Test. This was done seven days after the first post training test was given to the subject to establish tester reliability.

\section{THE RESPONSE EVENTS}

The response elicited during all testing was operationally defined as the subject pointing or giving the examiner one object out of several lying on the table. This was done in response to a question or statement given visually--orally but without voice--by the examiner.

The response during the oral-gestural training was operationally defined as the subject verbalizing "same" or "different" to the pairs of oral-gestures presented by the examiner. An example of this would be item 1, Appendix B, "Open mouth wide - two second pause - Open mouth wide", by the examiner. The subject response to this stimulus would be to verbalize "same" or "different" according to the sophistication of his discrimination ability.

\section{THE PROCEDURES}

This clinical study was carried out in three parts. The first part included obtaining a baseline score on the revised Children's Speechreading Test. The second part was the oral-gestural training 
period. The last part of the study involved retesting speechreading in order to compare the post training scores and the baseline scores. Prior to any testing or training, each of two classrooms participating in the study was visited by the examiner for two full days and there were periods of interaction with the children during both structured and unstructured situations. This acquaintance period was included in the event that some of the children might be afraid to go out of the security of the class room with a complete stranger.

During the baseline speechreading test, instructions were given to each subject by the examiner (see Appendix C). Each time a new set of items or pictures was presented they were either identified for the child or he was given the opportunity to identify them for himself to insure that the items were within his repetoire. The carrier phrase to be used, show me the..., point to the... etc., was given verbally each time a new set of items or pictures to be identified were presented and the child was to respond by pointing. A similar statement was then presented by the examiner without voice. If the subject did not watch the mouth and face area of the examiner for the complete statement he was told to "watch carefully" and/or "watch until I'm all through", and then the statement was repeated. Specific instructions to "watch my lips" or "watch my mouth" were not given. If a subject had a tendency to play or look at the test items instead of the examiner, the examiner would cover the items with her hand until 
the statement was completed.

If the subject was attending and indicated that he did not understand, the statement was repeated a second time. If the subject still indicated that he did not understand he was encouraged to guess by the examiner's question, "Which one do you think I said?" If the subject still hesitated, the examiner repeated the statement using a low voice, but the child was not given credit for the discrimination of that item. The revised Children's Speechreading Test takes forty-five to sixty minutes to administer. If the child appeared restless during testing, the examiner would move ahead to items sixty-s even through seventy which involves physical activity (see Appendix A). In this manner the child was allowed a change in activity without interrupting or prolonging the testing procedure.

An arbitrary number of twenty-five correct responses was set as the cut-off between poor and good speechreaders. If a subject gave twenty-five or less correct answers, indicating poor speechreading ability, he was then retested seven to ten days later by a second examiner. Identical instructions and reinforcement for responses were used in the second testing period. The revised Children's Speechreading Test was given to twenty-three children by two different examiners to ascertain tester reliability. Children's scores that varied less than five points between the two examiners were considered as reliable baseline data for speechreading ability. Ten children, 
whose scores showed a five point or less difference between the two testings were chosen on the basis of "poor"speechreading ability. "Poor" speechreading ability was defined by twenty-five or less correct responses out of a possible score of seventy on the revised Children's Speechreading Test.

After the baseline data for speechreading ability were determined, the examiner gave the instructions for the oral-gestural training to the subject (see Appendix C). The twenty-five oral-gesture pairs were given to each subject. If there appeared to be a great deal of hesitation, perseveration or any other indication that the subject did not understand the concept of "same and different", time was taken to teach this necessary concept for this task. The concept of "same and different" was taught by a pre-training discrimination task involving colors, sizes, body-gestures such as pointing, and finally oralgestures. 


\section{CHAPTER IV}

\section{RESULTS}

The fact that speechreading skills for propositional words can be acquired by means of visual discriminative training in oral facial movements has been demonstrated by this study. Table 1 summarizes the data derived during the Oral-Gestural Training Program. Variability between the two test scores, baseline and post training, was minimal. No child's test score varied more than five points on either set of data. The number of oral-gestural training sessions varied according to the number of twenty minute periods required for each subject to obtain the 100 percent criterion for each of the five groups of five oral-gesture stimulus pairs. Increase of test scores between the baseline speechreading score, and the post test score, after oralgestural training, varied from 13 to 27 points.

A comparison of pre-and post-training speechreading scores (Table II) shows a mean increase of 18.7 correct responses for the group. A mean of 4.3 sessions was required to reach the criterion of 100 percent correct response. A range of two to eight sessions was necessary for each individual child.

A t-test (Thompson, 1965) of the differences between the baseline mean and post training speechreading mean revealed significance 
TABLE I

A SUMMARY OF DATA DERIVED F ROM THE ORAL-GESTURAL TRAINING PROGRAM

\begin{tabular}{|c|c|c|c|c|c|c|c|c|}
\hline Subject & Sex & Age & PreTest I & PreTest II & $\begin{array}{l}\text { No. of } \\
\text { Training } \\
\text { Sessions }\end{array}$ & PostTest I & PostTest II & Increase \\
\hline 1 & $\mathbf{M}$ & 5 & 25 & 21 & 3 & 46 & 51 & 21 \\
\hline 2 & $\mathbf{M}$ & 5 & 14 & 10 & 4 & 29 & 30 & 14 \\
\hline 3 & $\mathbf{M}$ & 4 & 9 & 12 & 5 & 25 & 23 & 16 \\
\hline 4 & $\mathbf{M}$ & $5-1$ & 15 & 12 & 4 & 27 & 30 & 12 \\
\hline 5 & $\mathbf{F}$ & $4-6$ & 25 & 23 & 6 & 38 & 39 & 13 \\
\hline 6 & $\mathbf{M}$ & $4-5$ & 23 & 25 & 2 & 38 & 39 & 15 \\
\hline 7 & $F$ & $4-8$ & 20 & 15 & 3 & 47 & 47 & 27 \\
\hline 8 & $\mathbf{M}$ & $5-1$ & 25 & 28 & 4 & 48 & 46 & 23 \\
\hline 9 & $\boldsymbol{F}$ & $4-8$ & 19 & 19 & 8 & 38 & 40 & 19 \\
\hline 10 & $\mathbf{F}$ & $4-8$ & 20 & 21 & 4 & 47 & 47 & 27 \\
\hline
\end{tabular}


TABLE II

INCREASE IN SPEECHREADING SCORES AFTER ORAL-GESTURE TRAINING

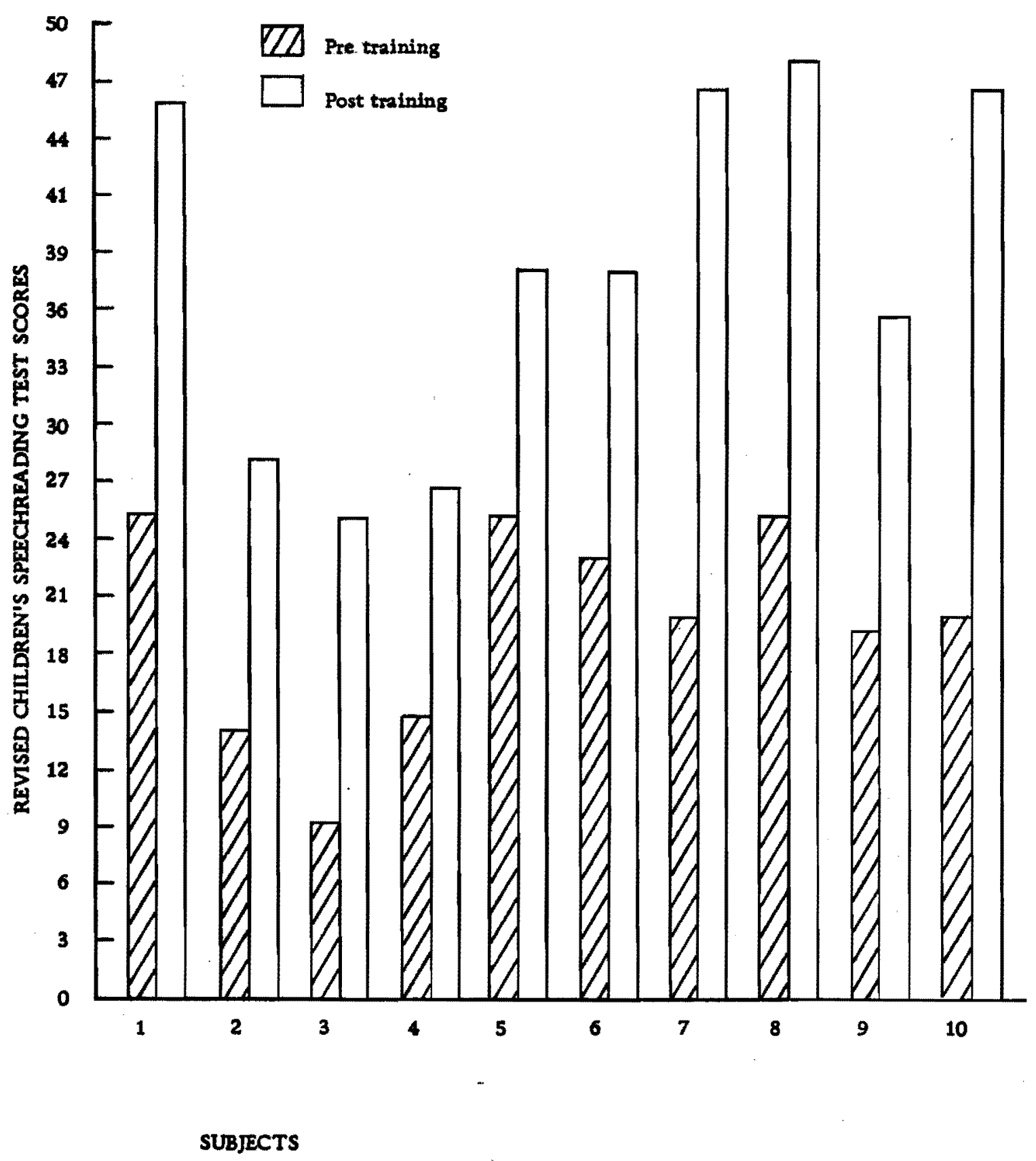

Mean increase of speechreading scores: 18.7

Mean number of oral-gesture training sessions: 4.3 
beyond the .05 level of confidence.

Within the limitations of the sample studied, it would appear from the data listed in Table III that on the average,girls made a larger gain in speechreading skills following the oral-gestural training than boys. However, since it took the girls a greater number of training periods (an average of 5.3 sessions) to achieve the 100 percent criterion for each group of five oral-gesture pairs than it did the boys (an average of 3.6 sessions), this additional exposure may have influenced the post training scores. Girls had a mean increase in speechreading scores of 21 points with a mean of 5.3 sessions while boys mean increase was 17 points with a mean of 3,6 sessions.

As can be seen in Table IV, the five year old group took less oral-gestural training sessions to reach the 100 percent criterion on each of the five groups of stimulus pairs. The four year-old group averaged more oral-gestural training sessions but the gain in post training speechreading scores was greater than the five year-old group. The four year-old group took an average of 4.7 training sessions to reach the discrimination criterion of 100 percent but the mean increase in speechreading scores was twenty points. The five yearolds took an average of 3.8 training sessions to reach criterion but their mean increase in speechreading scores was only eighteen points. This perhaps again suggests that additional exposure to the oralgetural training may have influenced the post oral-gestural training 
TABLE III

MEAN INCREASE WN SPEECHREADING SCORES

AGE-

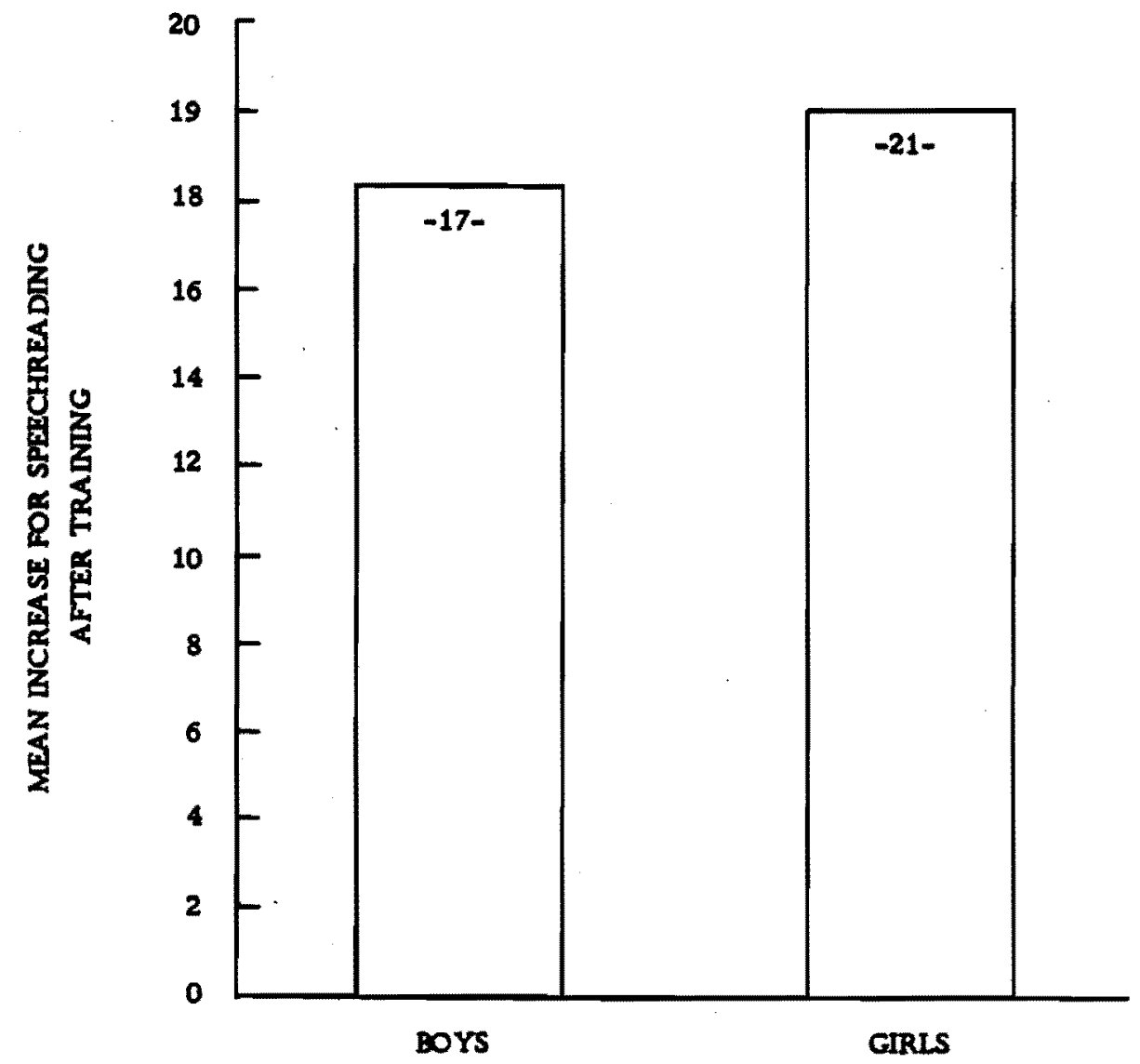

AVERAGE NUMBER

OF SESSIONS

3. 6

5. 3 
TABLE IV

MEAN INCREASE IN SPEECHREADING SCORES

$-A G E-$

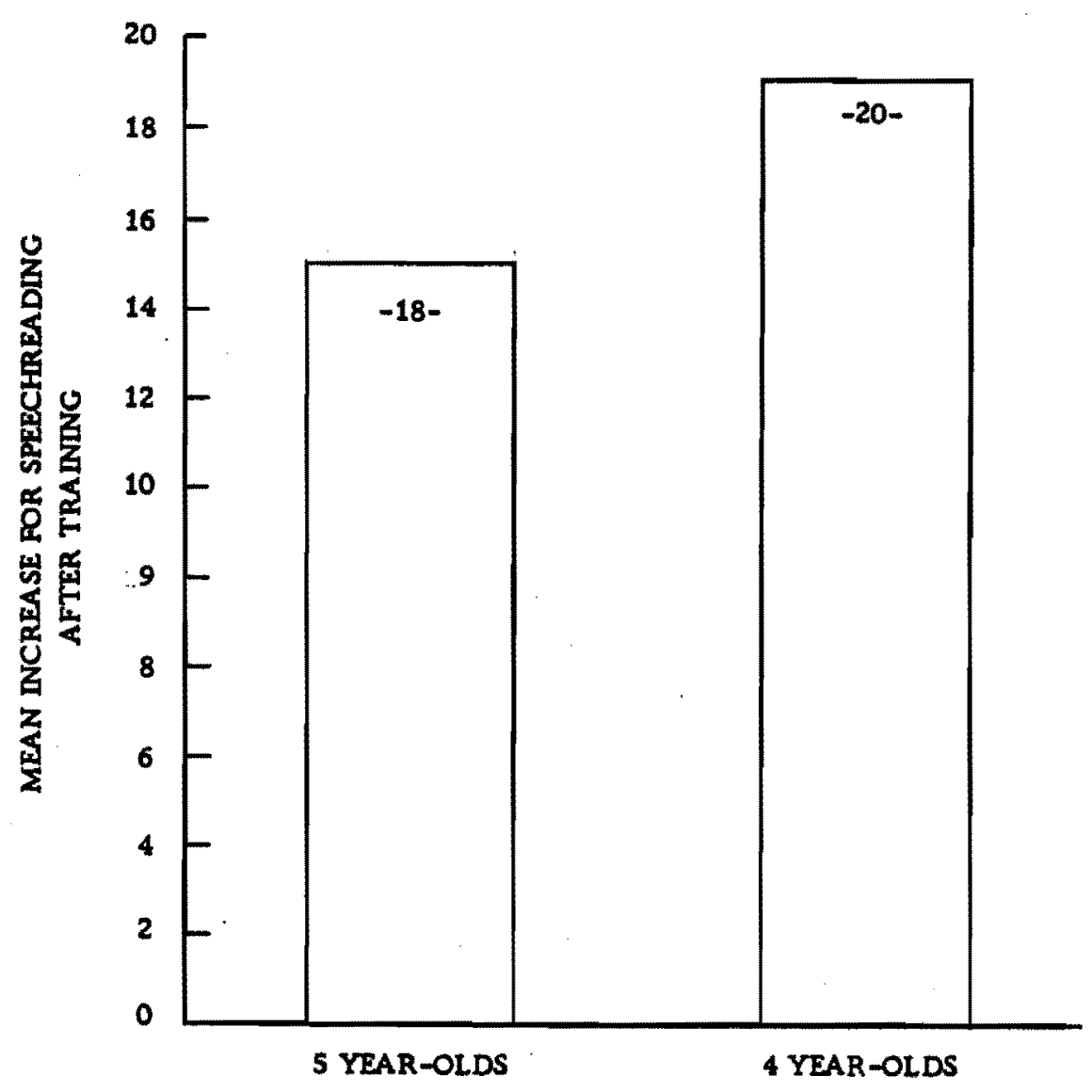

A VERAGE NUMBER

OF SESSIONS

3.8

4.7 
speechreading test scores.

Limitations that became apparent as this study progressed were the small size of the sample that was tested and trained and the less than ideal testing and training environment. Children who were tested were normal hearing subjects and language had already been established, which still leaves the question of the performance of prelingual, hearing handicapped children. Also, subjects were "randomly" chosen from the classroom rather than selection following a table of random order which may have biased the sample. Although no formal data was obtained on attention responses, it was observed subjectively that this capacity improved markedly among these subjects. This is a clinical observation and should be subjected to further investigation. 


\section{CHAPTER V}

\section{SUMMARY AND CONCLUSIONS}

\section{PURPOSE OF THE STUDY}

It is important for the prelingual hearing handicapped child to acquire language early so that he may take advantage of a child's natural capacity for language acquisition which peaks at two to four years and declines steadily thereafter. Speechreading is an important avenue for communication and establishing language for the deaf. However, at the present time most visual speechreading methods re quire the use of language. If speechreading can be regarded as a learning process involving the discrimination of visual cues, such as oral-gestures, then training aimed at teaching the child to discriminate small changes in facial movements may well provide for some of the same behaviors necessary for speechreading language responses. If such a training method proved to be highly connected with speechreading training, then it also might prove useful in helping the hearing handicapped preschool child acquire the necessary behaviors consistent with speechreading, namely visual.discrimination.

\section{THE TRAINING PROGRAM}

Ten four and five year old preschool children participated in the 
oral-gesture training program. A baseline speechreading test score was obtained through the use of the revised Children's Speechreading Test. Each child who continued in the study scored twenty-five or les o correct responses on the revised Children's Speechreading Test, arbitrarily chosen as indicating poor speechreading ability. To verify that a reliable speechreading test score was obtained, two separate speechreading test scores were required, each being within five points between the two examiners.

Oral-gestures, facial postures not associated with language expression, were then presented to the subject by the examiner in pairs. The subject was to discriminate whether the oral-gesture pair was the same both times or different each time and respond accordingly by saying "same" or "different". A 100 percent criterion was obtained by the child for a group of five oral-gesture pairs before proceeding to the next group of oral-gesture pairs. There were five groups of oral-gesture pairs or twenty-five oral-gesture pairs in total. Reinforcement for correct responses was based on a fixed interval schedule. Effectiveness of the oral-gestural training was assessed through re-administration of the revised Children's Speechreading Test.

\section{RESULTS}

The results of this study ascertained that speechreading skills 
for propositional words can be acquired by means of visual discrimination training for movements of the oral structures. After the oralgestural training, scores on the revised Children's Speechreading Test scores increased from 13 to 27 points among the ten subjects. Further conclusions of this study indicate that neither sex nor age (four or five year-olds) are important variables in increased speechreading ability after oral-gestural training. With this particular sample girls achieved a greater gain in speechreading ability after the oral-gestural training than did the boys. The mean increase in speechreading scores for girls was twenty-one while for boys the mean increase was seventeen and was not considered significant. It was also found that the greater the number of oral-gestural training sessions needed by a subject to achieve the 100 percent criterion for discrimination of oral-gesture pairs, the higher his post training speechreading test score.

\section{CONCLUSIONS}

Learned behavior of discriminating visual cues can be increased by a training program designed to develop and reinforce this behavior. Furthermore, such learning tends to increase speechreading ability as indicated by a t-test of the difference between the baseline mean and post training speechreading mean which revealed significance beyond the .05 level of confidence. 
Findings of this study seem to indicate that exposure to oralgestural training is a more significant variable than sex or age between the four and five year-olds tested. The number of oral-gestural training sessions received by the subject appears to be directly related to the amount of increased speechreading ability.

It is proposed that the use of the Oral-Gestural Training Program for the prelingual hearing handicapped as submitted in this study, would require no oral response for either the revised Children's Speechreading Test or the oral-gestural training. A response could be made through pointing for the speechreading test. The oralgesture discrimination could be communicated through body gestures such as nodding the head up and down or sideways for yes or no, or the child could place his hand on selected colors for "same" or "different" responses, i. e., pink for "same" and green for "different".

\section{IMPLICATIONS FOR FURTHER STUDY}

Since this study involved normal hearing children in a program specifically designed for the deaf and hard-of-hearing child, there seems to be several distinct areas where further research is possible. Will a population of hearing handicapped children confirm the positive results of this study? Does the specific number of oral-gestural training sessions significantly affect the post training test score for speechreading? Will a larger sample of children find the same sex 
differences and differences between age groups as found in the present study?

All of these questions are possible areas for further research and may support an earlier statement--that if such a training method proved to be highly connected with speechreading training, then it also might prove useful in helping aurally handicapped, prelingual children acquire the necessary behaviors consistent with speechreading. 
Bode, Daniel L., Nerbonne, G. Patrick, and Sahlstrom, Lowell J., "Speechreading and the Synthesis of Distorted Printed Sentences." Journal of Speech and Hearing Research. 12, 115 121 (1970).

Butt, Delores S., and Chreist, Fred M., "A Speechreading Test for Young Children." Volta Review, 70, $225-245$ (1968).

Davis, Hallowell, and Silverman, S. Richard, Hearing and Deafness. New York: Holt, Rinehart and Winston (1970).

DeLand, Fred, The Story of Lip Reading: Its Genesis and Development. Washington, D. C.: The Volta Bureau (1931).

DiCarlo, Louis M. , The Deaf. Englewood Cliffs, New Jersey: Prentice-Hall Foundations of Speech Pathology Series (1964).

Ewing, Irene, "Eleanor Has Made History. What Next?" Volta Review, 68, $151-157$ (1966).

Fry, D. B., "The Development of the Phonological System in the Normal and the Deaf Child, "in F. Smith and G. A. Miller (Eds.), The Genesis of a Language, a Psycholinguistic Approach. Cambridge, Mas8.: MIT Pres8, 187-206 (1966).

Fusfeld, Irving S. (Ed.) A Handbook of Reading in Education of the Deaf and Post School Implications. Springfield, Illinois: Charles C. Thomas Publisher (1967).

Gessell, A. L., and Amatruda, Catherine S., Developmental Diagnosis: Normal and Abnormal Child Development. New York: Paul B. Hoeber, Inc. Medical Department of Harper and Brothers (1947).

Goldstein, M. A., Problems of the Deaf. St. Louis: The Laryngoscope Press (1933).

Heider, F., and Heider G., "An Experimental Investigation of Lip Reading." Psychological Monographs, $52,1-153$ (1940). 
Maurer, James F., "Sustaining and Shaping Vocal Behavior in Prelingual Deaf Preschool Children." Unpublished Doctoral

Dissertation. Eugene, Oregon: Department of Speech, University of Oregon (1968).

McNeill, David, "The Capacity for Language Acquisition." The Volta Review, 68, 17-33 (1966).

O'Neill, John J., "Contributions of the Visual Components of Oral Symbols and the Speech Compression of Listeners with Normal Hearing. " Unpublished Doctoral Dissertation. Columbus, Ohio: Department of Speech, Ohio State University (1951).

O'Neill, John J., "Exploratory Investigation of Lipreading Ability Among Normal Hearing Students." Speech Monographs, 18, 309-311 (1951).

O'Neill, John J., and Davidson, JoAnn L., "Relationship Between Lipreading Ability and Five Psychological Factors." Journal of Speech and Hearing Disorders, 4, 478-481 (1956).

O'Neill, John J., and Oyer, Herbert J., Visual Communication for the Hard of Hearing: History, Research, and Methods. Engle- wood Cliffs, New Jersey: Prentice-Hall, Inc. (1961).

Pinter, R., "Speech and Speechreading Tests for the Deaf." Journal of Appl. Psychol., 4, 220-225 (1929).

Russell, Mary E., and Folsom, Richard C., "Revised Children's Speechreading Test." Unpublished revision of the Children's Speechreading Test. Portland, Oregon: Department of Speech, Portland State University (1969).

Simmons, Audrey Ann, "Factors Related to Lipreading." Journal of Speech and Hearing Disorders, 4, 340-344 (1959).

Thompson, Richard F., Statistical Methods Useful in Medicine. Portland, Oregon: Départment of Public Health and Preventative Medicine (1965). 
APPENDICES 


\author{
APPENDIX A \\ CHILDREN'S SPEECHREADING TEST* \\ Revised 1969 \\ Mary E. Russell \\ Richard C. Folsom \\ - Portland State University
}

Name Speechreading Test Score

School Test Date

Examiner Birthdate

Years of Training Age Sex

Hearing: Right Left

Age and Cause of Hearing Loss

TEST A: INFORMAL CHECKLIST FOR CHILDREN UNDER THREE YEARS OF AGE

Normal age of

appearance

2 months 1. Does child attend to face?

10 months 2. Does child respond to gesture? (Pat-a-cake, Bye-bye, etc.)

12 months 3. Does child inhibit on command? (No-no gesture)

18 months 4. Does child understand simple questions? (Where's Daddy?)

21 months 5. Will child follow simple commands ? (Give it to me: Come here: etc.)

* Taken from: Butt, Dolores S., Fred M. Chreist, "A Speechreading Test for Yaung Children," Volta Review, Volume 70, No. 4, April 1968, p. 231. 
24 months 6. Can be speechread his own name?

The name of others?

Objects? (milk, show, etc.)

Or concepts? (up, hot, good)

(no norms) 7. Can he repeat the words he speechreads?

(Hello, Mama, etc.)

8. Can he answer questions?

(What is your name? How are you?)

GENERAL DIRECTIONS TEST B

Examiner should sit approximately 4 feet from the child in a welllighted room. The child's attention should be directed to the examiner's face before presenting any material. A voiced presentation should be given for each item in each part of the test to familiarize the child with the name of the objects for that presentation.

In presenting the test itself, the child should be spoken to naturally but in an inaudible voice. If the child responds incorrectly, go on to the next item. * If the child does not respond to the item, present a 2nd and $3 \mathrm{rd}$ time if needed. Noting whether correct response was made to the 2nd or $3 \mathrm{rd}$ presentation may be of interest in analyzing the test results. This however, does not affect the child's score on the test.

\section{SCORING}

Each correct answer receives one point. Correct answers are credited even if the child seems to be guessing. * The number correct subtracted from 70 is the child's score.

\section{TEST MATERIAL}

1. Toys, durable and realistically colored, and in correct proportion:

3" baby doll

1" baby doll

doll bed, table, and chair

doll shoe

car

airplane bell

cellophane wrapped candy

toy cup, fork and spoon

$1^{\prime \prime}$ rubber ball

$1 / 2$ " rubber ball

child's toothbrush

* The specific class responses will vary with the task. 


$\begin{array}{ll}\text { bus } & \text { cow } \\ \text { train } & \text { hat } \\ \text { gun } & \text { chicken } \\ \text { top } & \text { pig } \\ \text { toy wristwatch } & \text { horse } \\ \text { button } & \text { fish } \\ & \text { sheep }\end{array}$

2. Blocks: five 1" counting blocks of uniform color.

3. Color chips: 1" colored paper squares: yellow, blue, black, red, brown, and white

4. Ten 5" $\times$ 7" (minimum size) cards constructed from colored pictures in children's books or magazines. Each card contains one of the picture groups below. Each picture must be realistic and easily recognized by a child:

(a) baby, kitten, flower

(b) mother, father, boy, girl

(c) bird, dog, hammer, spoon

(d) television set, sail boat, house, bed

(e) boy putting on his shoes;

boy eating at the table;

girl or boy or both swimming

(f) child playing with a ball;

dog getting a bath;

girl jumping rope

(g) child playing with blocks;

child in bed;

child reading a book

(h) apple, water faucet, pie, butter

(i) an orange, milk glass

(j) banana, cookies, cooked meat, soup

5. Paper dolls with clothes: girl and boy dolls should be mounted on separate 8-1/2" X 11 " cards, and the clothing should be cut so that it can easily be placed in position. The boy doll should have; pants, shirt, pajamas, hat, coat, and shoes. The girl doll should have: dress, pajamas hat, coat, and shoes. 


\section{PART I: IDENTIFICATION OF OBJECTS}

ITEM FAMILIARIZ ATION EXERCISE-Using voice, present all 4 objects of the first phase on the table in order. Identify by saying "This is a (an) (object name)." Use the Item Familiarization Exercise (I.F.E.) for each succeeding phase prior to its test presentation.

TEST-Place the group of 4 objects for the first phase on the table. Without voice present each stimulus below. The child is required to indicate the appropriate object. Remember to use the I.F. E. before each test presentation.

PHASE (a)--Present: fish, shoe, ball, train

1. Show me the fish. 2. Show me the ball.

3. Show me the shoes.

FAMILIARIZE THE CHILD WITH THE ITEMS OF THE NEXT PHASE

PHASE (b)--Present: top, airplane, baby, gun

4. Show me the airplane. 5. Show me the top.

6. Show me the gun.

FAMILIARIZE THE CHILD WITH THE ITEMS OF THE NEXT PHASE

PHASE (c)--Present: chair, toothbrush, button, table

7. Show me the chair. 8. Show me the button.

9. Show me the toothbrush.

FAMILIARIZE THE CHILD WITH THE ITEMS OF THE NEXT PHASE 
PHASE (d)--Present: fork, table, car, bus

10. Show me the table. 11. Show me the car.

12. Show me the bus.

FAMILIARIZE THE CHILD WITH THE ITEMS OF THE NEXT PHASE

PHASE (e)--Present: candy, watch, bell, hat

13. Show me the bell. 14. Show me the candy.

15. Show me the watch.

PART II: NUMBERS

ITEM FAMILIARIZA TION EXERCISE--Place 5 blocks on the table. Push 4 blocks toward the child and, using voice, say "four". In order. Do the same with the other numbers, one through five. Encourage the child to push the blocks toward the tester in response to the tester's voiced stimulus. Continue until the child feels certain of the task required.

TEST-Place 5 blocks on the table. Without voice, present the stimulus in the order indicated below. A correct response would be an indication by the child of the correct number.

PHASE (a)--Present:

16. one. 17. three. 18. two.

PART III: PICTURE IDENTIFICATION

ITEM FAMILIARIZATION EXERCISE--Using voice, present each item on the picture test card and identify it to the child by saying, "This is a (name)." Use this I.F.F. for each succeeding phase prior to its test presentation.

TEST -Present picture test card to child. Without voice, present each stimulus below. Child is required to indicate the appropriate picture. 
PHASE (a)--Present: test card (a)

19. Where is the baby? 20. Where is the flower?

FAMILIARIZE THE CHILD WITH THE ITEMS OF THE NEXT PHASE

PHASE (b)--Continue with test card (b)

21. Where is mother? 22. Where is father?

23. Where's the boy?

FAMILIARIZE THE CHILD WITH THE ITEMS OF THE NEXT PHASE

PHASE (c)--Continue with test card (c)

24. Point to the bird. 25. Point to the dog.

26. Point to the hammer.

FAMILIARIZE THE CHILD WITH THE ITEMS OF THE NEXT PHASE

PHASE (d)--Continue with test card (d)

27. Point to the T.V. 28. Point to the boat.

29. Point to the house.

PART IV: COLOR IDENTIFICATION

ITEM FAMILIARIZ ATION EXERCISE--Using voice, present each color square by pointing to the color and saying the name of the color to the child.

TEST - Lay the group of three colors on the table. Without voice present the stimulus below. The child is required to indicate the appropriate color. 
PHASE (a)--Present: blue, yellow, and white.

30. blue

WITHDRAW THE GROUP OF COLORED CHIPS AND PROCEED TO THE NEXT I. F.E.

PHASE (b)--Present: black, white, and brown.

31. white

WITHDRAW THE GROUP OF COLORED CHIPS AND PROCEED TO THE NEXT I.F.E.

PHASE (c)--Present: yellow, brown, and red.

32. brown

\section{PART V: ACTIONS}

ITEM FAMILIARIZ ATION EXERCISE--Using voice, present each action on the picture test card and identify it to the child by saying, "This boy (or girl) is (action)." Use this I. F.E. for each succeeding phase prior to its test presentation.

TEST-Present picture test card to child. Without voice, present each stimulus to follow. The child is required to indicate the appropriate action picture.

PHASE (e)--Present test card (e)

33. Who puts on his shoes?

34. Who eats his supper?

F AMILIARIZE THE CHILD WITH THE ITEMS OF THE

NEXT PHASE

PHASE (f)--Continue with test card (f)

35. Which one plays ball?

36. Which one takes a bath? 
FAMILIARIZE THE CHILD WITH THE ITEMS OF THE NEXT PHASE

PHASE (g) --Continue with test card (g)

37. Who is in bed?

38. Who reads a book?

PART VI: FOODS

ITEM FAMILIARIZATION EXERCISE--Using voice, present pictures of each food item and identify it to the child by saying, "This is a (an) (food item)." Use the I. F. E. for each succeeding phase prior to its test presentation.

TEST-Present picture test card to child. Without voice, present each stimulus below. The child is required to indicate the appropriate picture.

PHASE (h)--Present test card $(\mathrm{h})$

39. Show me the apple. 40. Where is the water?

41. Point to the pie.

FAMILIARIZE THE CHILD WITH THE ITEMS OF THE NEXT PHASE

PHASE (i)--Continue with test card (i)

42. Show me the orange. 43. Where is the milk?

44. Where is the bread?

F AMILIARIZE THE CHILD WITH THE ITEMS OF THE NEXT PHASE

PHASE (j) --Continue with test card (j)

45. Show me the banana. 46. Where are the cookies?

47. Show me the meat. 


\section{PART VII: DESCRIPTIVE WORDS}

ITEM FAMILIARIZATION EXERCISE-Using voice, present all 4 objects for this part, (a big ball and a little ball, a $3^{\prime \prime}$ baby doll and a 1" baby doll), in order. Identify each by saying, "This is a big/little (object).

TEST-Place all 4 items on the table. Without voice, present each stimulus below. The child is required to indicate the correct object and size each time.

48. Give me the big baby. Give me the little baby.

49. Give me the big ball. Give me the little ball.

\section{PART VIII: PARTS OF THE BODY}

ITEM FAMILIARIZATION EXERCISE-Using voice, say to the child, "This is my face. Where is your face? Show me your face." When the child understands, identify your mouth, eyes, nose, teeth, arm and feet in order.

TEST -Without voice, present each stimulus below. The child is required to point to the appropriate body part.

50. Show me your arm. 51. Where are your eyes?

52. Where are your feet? 53. Where is your mouth?

54. Show me your teeth. 55. Where is your nose?

\section{PART DX: ANIMAL NAMES}

ITEM FAMILIARIZATION EXERCISE--Place these 5 animals on the table in the following order: chicken, pig, sheep, cow, horse. Using voice, identify each animal to the child by saying, "This is a (an) (animal)."

TEST-Without voice, present each stimulus below. The child must give the appropriate animal. 
56. Give me the cow.

58. Give me the pig.
57. Give me the horse.

59. Give me the chicken.

\section{PART X: CLOTHING}

ITEM FAMILIARIZATION EXERCISE--Place on the table a paper doll mounted on a card approximately 8-1/2" X $11^{\prime \prime}$. Use a boy or girl doll according to the sex of the child. Place the doll's clothes beside the test card. Using voice, demonstrate each item by placing it on the doll and saying, "This is his (her) (clothing article). " Present in the following order: Boypants, shirt, pajamas, hat, coat, shoes; Girl-dress, pajamas, hat, coat, shoes.

TEST-Without voice, direct the child through each of the following stimuli. The child is required to follow directions exactly for correct response.

60. Put on his (her) shoes.

62. Put on his shirt (her dress).
61. Put on his (her) coat.

63. Put on his (her) hat.

\section{PART XI: SIMPLE DIRECTIONS}

ITEM FAMILIARIZATION EXERCISE--Place on the table the following objects: chair, bed, baby, cup, table, spoon, fork. Using voice, identify each object to the child in order.

TEST-Place all 7 objects on the table. Without voice, direct the child through each of the following stimuli. The child must follow the complete stimuli exactly for correct response.

64. Put the baby to bed.

65. Put the spoon in the cup.

66. Put the fork on the table. 
PART XII: ACTIVITIES

ITEM FAMILIARIZATION EXERCISE--Stand up and gesture for the child to stand. Using voice, say, "Stand up. Do what I do. Can you hop?" Hop and encourage the child to perform this action as a demonstration. Using voice, demonstrate each of the following activities: walk, come here, open the door, jump: in order.

TEST-Without voice, direct the child through each of the following stimuli. The child must follow stimuli exactly for correct response.

67. Can you jump?

68. Walk to the door.

69. Open the door.

70. Come here. 
APPENDIX B

ORAL'GESTURAL SCHEDULE

NAME

DATE

\begin{tabular}{|c|c|c|c|c|}
\hline 1. & $\begin{array}{l}\text { Open mouth wide. } \\
\text { Open mouth wide. }\end{array}$ & 3 & 5 & 4 \\
\hline 2. & $\begin{array}{l}\text { Open mouth wide. } \\
\text { Open mouth; tongue straight } \\
\text { out. }\end{array}$ & 5 & 4 & 2 \\
\hline 3. & $\begin{array}{l}\text { Open mouth; tongue straight } \\
\text { out. } \\
\text { Open mouth; tongue straight } \\
\text { out. }\end{array}$ & 2 & 3 & 5 \\
\hline 4. & $\begin{array}{l}\text { Open mouth wide. } \\
\text { Open mouth; bite lower lip. }\end{array}$ & 1 & 2 & 3 \\
\hline 5. & $\begin{array}{l}\text { Open mouth; bite lower lip. } \\
\text { Open mouth; bite lower lip. }\end{array}$ & 4 & 1 & 1 \\
\hline 6. & $\begin{array}{l}\text { Open mouth; bite tongue. } \\
\text { Open mouth; bite tongue. }\end{array}$ & 7 & 9 & 8 \\
\hline 7. & $\begin{array}{l}\text { Open mouth; bite lower lip. } \\
\text { Open mouth; bite tongue. }\end{array}$ & 9 & 6 & 10 \\
\hline 8. & $\begin{array}{l}\text { Pooch or pucker lips. } \\
\text { Open mouth wide. }\end{array}$ & 6 & 8 & 7 \\
\hline 9. & $\begin{array}{l}\text { Pooch or pucker lips. } \\
\text { Pooch or pucker lips. }\end{array}$ & 10 & 7 & 6 \\
\hline 10. & $\begin{array}{l}\text { Open mouth; tongue to alveolar } \\
\text { ridge. } \\
\text { Open mouth; tongue straight } \\
\text { out. }\end{array}$ & 8 & 10 & 9 \\
\hline
\end{tabular}




\begin{tabular}{|c|c|c|c|c|}
\hline 11. & $\begin{array}{l}\text { Open mouth; bite tongue. } \\
\text { Open mouth; tongue to alveolar } \\
\text { ridge. }\end{array}$ & 15 & 13 & 12 \\
\hline 12. & $\begin{array}{l}\text { Open mouth; tongue to alveolar } \\
\text { ridge. } \\
\text { Open mouth; tongue to alveolar } \\
\text { ridge. }\end{array}$ & 14 & 15 & 11 \\
\hline 13. & $\begin{array}{l}\text { Open mouth; tongue side to } \\
\text { side (3). } \\
\text { Open mouth; tongue side to } \\
\text { side (3). }\end{array}$ & 13 & 11 & 14 \\
\hline 14. & $\begin{array}{l}\text { Draw corners of mouth back for } \\
\text { smile. } \\
\text { Pooch or pucker lips. }\end{array}$ & 12 & 12 & 13 \\
\hline 15. & $\begin{array}{l}\text { /1a/off upper incisors; tongue } \\
\text { out. } \\
\text { /1a/off upper incisors; tongue } \\
\text { out. }\end{array}$ & 11 & 14 & 15 \\
\hline 16. & $\begin{array}{l}\text { Draw corners of mouth back } \\
\text { for smile. } \\
\text { Open mouth wide. }\end{array}$ & 17 & 20 & 18 \\
\hline 17. & $\begin{array}{l}\text { Thrust tongue into check (either). } \\
\text { Open mouth wide; bite lower lip. }\end{array}$ & 19 & 19 & 16 \\
\hline 18. & $\begin{array}{l}\text { Open mouth; bite upper lip. } \\
\text { Open mouth; bite lower lip. }\end{array}$ & 20 & 18 & 17 \\
\hline 19. & $\begin{array}{l}\text { Open mouth; tongue up outside. } \\
\text { Open mouth; tongue down outside. }\end{array}$ & 16 & 17 & 20 \\
\hline 20. & $\begin{array}{l}\text { Open mouth; tongue out side } \\
\text { (either). } \\
\text { Open mouth; tongue side to } \\
\text { side (3). }\end{array}$ & 18 & 16 & 19 \\
\hline
\end{tabular}




\begin{tabular}{|c|c|c|c|c|}
\hline 21. & $\begin{array}{l}\text { Open mouth, tongue up out side } \\
\text { Open mouth; tongue up out side. }\end{array}$ & 23 & 25 & 22 \\
\hline 22. & $\begin{array}{l}\text { Thrust tongue into cheek } \\
\text { (either). } \\
\text { Thrust tongue into cheek } \\
\text { (same). }\end{array}$ & 21 & 24 & 24 \\
\hline 23. & $\begin{array}{l}\text { Open mouth; tongue out side } \\
\text { (either). } \\
\text { Thrust tongue into cheek } \\
\text { (same). }\end{array}$ & 25 & 23 & 21 \\
\hline 24. & $\begin{array}{l}\text { Open mouth; tongue to alveolar } \\
\text { ridge. } \\
\text { /La/ off upper incisors; tongue } \\
\text { out. }\end{array}$ & 24 & 22 & 25 \\
\hline 25. & $\begin{array}{l}\text { Open mouth; bite upper lip. } \\
\text { Open mouth; bite upper lip. }\end{array}$ & 22 & 21 & 23 \\
\hline
\end{tabular}




\section{APPENDIX C}

\section{PRETEST INSTRUCTIONS}

I'm going to show you some toys and some pictures. Then I'm going to ask you some questions and you can point to the one you think I want, or give it to me. Sometimes I'm going to talk nice and loud, sometimes I'll just whisper, and sometimes you won't be able to hear me at all. Watch real close. When you can't hear, it's okay to guess the one you think I said. 


\section{APPENDIX D}

\section{ORAL-GESTURAL TRAINING INSTRUCTIONS}

We're going to do something different today. I'm going to make some movements with my mouth. I want you to tell me if I do the same thing twice so that they are the same or if I do two things that aren't the same--they will be different. You tell me "same" or "different". 


\section{APPENDIX E}

\section{POST TEST INSTRUCTIONS}

You remember my little boxes of toys and my pictures? Well I'm going to show them to you again today and ask you some questions. Sometimes I'll say them nice and loud, sometimes $I^{\prime} l 1$ just whisper and you won't be able to year me at all. Watch carefully so you can tell what I'm saying. 